\title{
ISB news September 2009
}

From the President

I am pleased to announce two important biometeorology conferences that will be taking place next year. The International Society of Biometeorology has recently shown its support for both conferences by becoming a sponsor of them. The first of the two conferences will be the 'BIOMET 7 Conference' from 12 to 14 April 2010, at the Albert-LudwigsUniversity, Freiburg, Germany. Organisers of the conference are the Meteorological Institute Albert-Ludwigs-University, Freiburg, and the Expert Committee on Biometeorology of the German Meteorological Society. A broad range of biometeorology topics will be covered by this conference. The deadline for submission of abstracts is 15 December 2009. The website for the conference, which includes information about topics, language, deadlines, registration, abstract submission, accommodation, and the Scientific Committee, is: http://www.mif.uni-freiburg.de/biomet/bm7
The other conference is 'Phenology 2010: Climate change impacts and adaptation' from 14 to 17 June 2010, at Trinity College, Dublin, Ireland. This conference aims to bring together experts from around the world in the fields of plant and animal phenology from both terrestrial and aquatic ecosystems. This conference will be an excellent opportunity for members of the ISB's Phenology Commission to meet. The website for the conference, which includes information about the conference programme, field trips, registration, information for authors, guidelines, abstract submission, a photography competition, and travel and accommodation, is: http://www.tcd.ie/Botany/phenology/2010

\section{Paul J. Beggs}

Department of Environment and Geography Macquarie University paul.beggs@mq.edu.au 